\title{
SYNTHESIS AND CHARACTERIZATION OF ALUMINUM METAL MATRIX COMPOSITES
}

\author{
K.Keerthi ${ }^{1}$ and R.Gayatri Devi ${ }^{2}$
}

\begin{abstract}
Copper has been the most common alloying element almost since the beginning of the aluminum industry, and a variety of alloys in which copper is the major addition were developed. Most of these alloys fall within one of the following groups:

$\mathrm{Al}$ and $\mathrm{Al}$ alloy based composites have been characteristics as futuristic materials for a number of engineering purposes. And the material are more preferred by engineers because of their great strength, low density, enhanced and tailored high refractoriness properties, stiffness and damping capabilities. The principle advantage is that MMCs can be use to a significantly higher temperature. Increasing quantities metal matrix composites MMCs being used to replace conventional materials in numerous applications, especially in the automobile and recreational industries. MMC's provide a better combination of Specific strength and modulus compared to monolithic alloys like aluminum, magnesium, copper, nickel and steel in relevance, commonly light weight and energy savings are essential design considerations. In recent years there was a great deal of interest in particulatereinforced metal-matrix composites (MMCs), and in particular those based on existing aluminum alloys.

Keywords - Aluminum, copper, metal matrix
\end{abstract}

\section{SPECIMEN PREPARATION}

Preparation of Aluminum Copper specimens:

Casting is a probably one of the most ancient processes of manufacturing metallic components. Also with few exceptions, it is the first step in the manufacture of metallic components. The process involves the following basic steps

A. Melting the metal.

2. Pouring it into a previously made mould or cavity which conforms to the shape of the desired component.

3. Allowing the molten metal to cool and solidify in the mould.

4. Removing the solidified component from the mould, cleaning it and subjecting it to further treatment, if necessary.

The solidified piece of metal, which is taken out the mould, is called as "casting". A plant where the castings are made is called a 'Foundry'. It is a collection of necessary materials, the tools and equipment to produce a casting. The casting process is also called as "Founding". The casting technique used is die casting.

\section{B. Die casting:.}

Two variants are pore-free die casting, which is used to eliminate gas porosity defects; and direct injection die casting, which is used with zinc castings to reduce scrap and increase yield.

Two dies are used in die casting; one is called the "cover die half" and the other the "ejector die half". Where they meet is called the paring line. The cover die contains the sprue (for hot-chamber machines) or shot hole (for cold-chamber machines), which allows the molten metal to flow into the dies; this feature matches up with the injector nozzle on the hot-chamber machines or the shot chamber in the cold-chamber machines. The ejector die contains the ejector pins and usually the runner, which is the path from the sprue or shot hole to the mold cavity. The cover die is secured to the stationary, or front, platen of the casting machine, while the ejector die is attached to the movable platen. The mould cavity is cut into two cavity inserts, which are separate pieces that can be replaced relatively easily and bolt into the die halves.

${ }^{1}$ Department of mechanical Engineering Aditya engineering college, Kakinada, A.P., India

${ }^{2}$ Department of mechanical Engineering Aditya engineering college, Kakinada, A.P., India 
The dies are designed so that the finished casting will slide off the cover half of the die and stay in the ejector half as the dies are opened. This assures that the casting will be ejected every cycle because the ejector half contains the ejector pins to push the casting out of that die half. The ejector pins are driven by an ejector pin plate, which accurately drives all of the pins at the same time and with the same force, so that the casting is not damaged. The ejector pin plate also retracts the pins after ejecting the casting to prepare for the next shot. There must be enough ejector pins to keep the overall force on each pin low, because the casting is still hot and can be damaged by excessive force. The pins still leave a mark, so they must be located in places where these marks will not hamper the castings purpose.

Other die components include cores and slides. Cores are components that usually produce holes or opening, but they can be used to create other details as well. There are three types of cores: fixed, movable, and loose. Fixed cores are ones that are oriented parallel to the pull direction of the dies (i.e. the direction the dies open), therefore they are fixed, or permanently attached to the die. Movable cores are ones that are oriented in any other way than parallel to the pull direction. These cores must be removed from the die cavity after the shot solidifies, but before the dies open, using a separate mechanism. Slides are similar to movable cores, except they are used to form undercut surfaces. The use of movable cores and slides greatly increases the cost of the dies. Loose cores, also called pick-outs, are used to cast intricate features, such as threaded holes. These loose cores are inserted into the die by hand before each cycle and then ejected with the part at the end of the cycle. The core then must be removed by hand. Loose cores are the most expensive type of core, because of the extra labor and increased cycle time. Other features in the dies include water-cooling passages and vents along the parting lines. These vents are usually wide and thin (approximately 0.13 $\mathrm{mm}$ or $0.005 \mathrm{in}$ ) so that when the molten metal starts filling them the metal quickly solidifies and minimizes scrap. No risers are used because the high pressure ensures a continuous feed of metal from the gate.

The most important material properties for the dies are thermal shock resistance and softening at elevated temperature; other important properties include harden ability, mach inability, heat checking resistance, weld ability, availability (especially for larger dies), and cost. The longevity of a die is directly dependent on the temperature of the molten metal and the cycle time. The dies used in die casting are usually made out of hardened tool steels, because cast iron cannot withstand the high pressures involved, therefore the dies are very expensive, resulting in high start-up costs. Metals that are cast at higher temperatures require dies made from higher alloy steels.

\section{PROCESS}

1. Melt metals

2. Pour or force liquid in to the hollow cavity

3. Cool or solidify

4. Remove

5. Surface finish

\section{TEST CONDUCTED}

1. Tension test

2. Impact test

3. Hardness test

4. Microstructure test
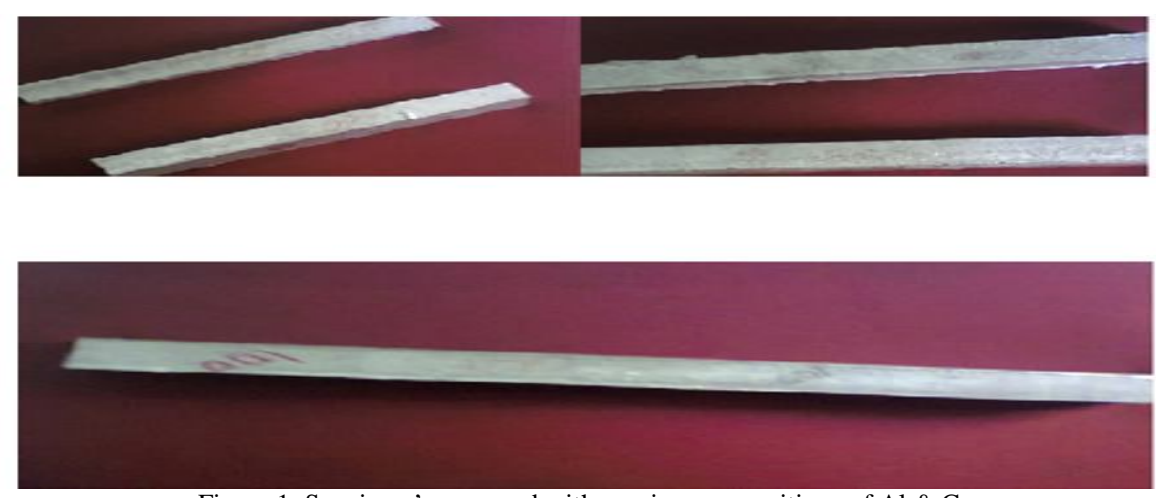

Figure 1. Specimen's prepared with varying compositions of $\mathrm{Al} \& \mathrm{Cu}$

\section{E. Microstructure}


Microstructure is defined as the structure of a prepared surface or thin foil of material as revealed by a microscope above $25 \times$ magnification. The microstructure of a material (which can be broadly classified into metallic, polymeric, ceramic and composite) can strongly influence physical properties such as strength, toughness, ductility, hardness, corrosion resistance, high/low temperature behavior, wear resistance, and so on, which in turn govern the application of these materials in industrial practice.

Reagent used is Keller's reagent.

Composition of Keller's reagent:

a. $92 \%$ Distilled water

b. $6 \%$ Nitric acid

c. $2 \%$ Hydrofluoric ac
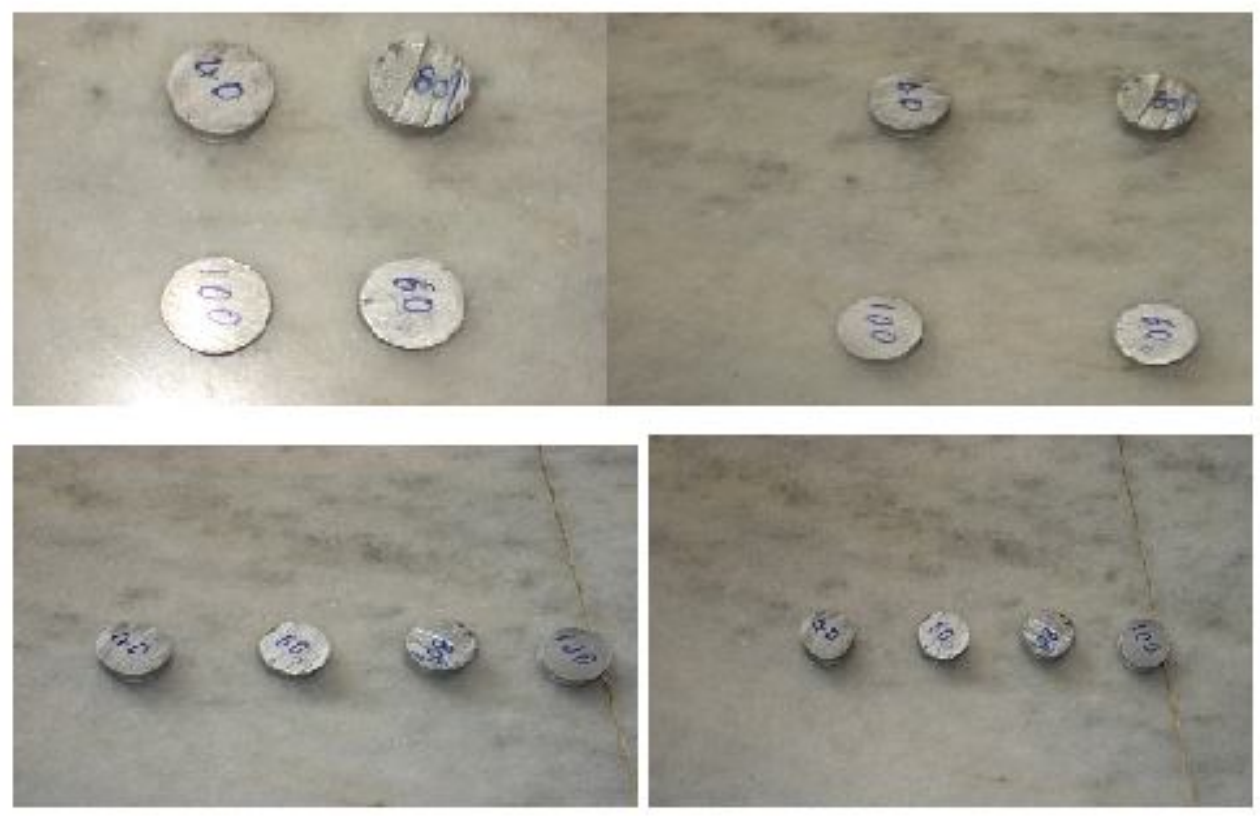

Figure 2. Specimen prepared for etching to study microstructure 
$4 \%$ COPPER

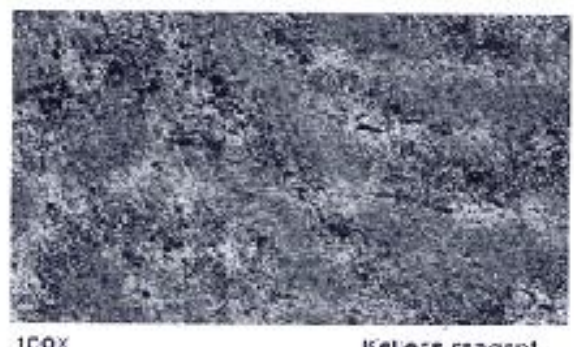

$1 \mathrm{cox}$ kelers ragant

\section{$6 \%$ COPPER}

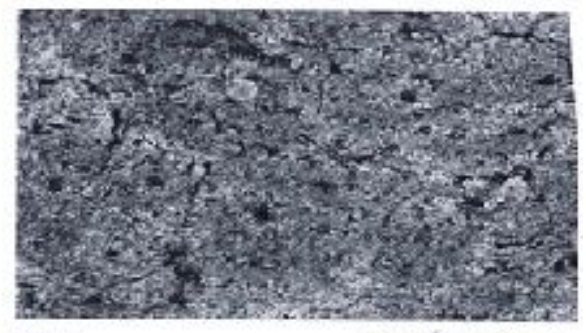

$1000 x$

Kellet'a rangent

\section{$8 \%$ COPPER}

\section{$10 \%$ COPPER}
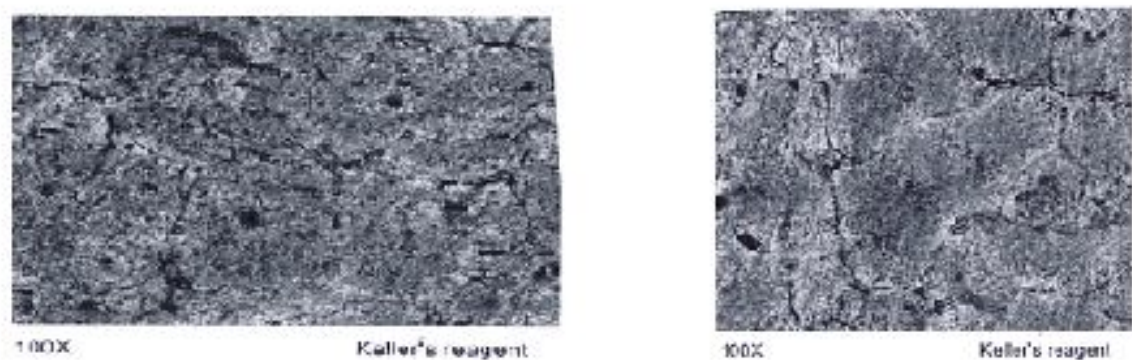

Kelleris ruagent

\section{II.RESULT}

Table -1 Experiment Result

\begin{tabular}{|l|l|l|l|l|}
\hline \% of aluminium & \%of copper & Tensile strength N/mm^2 & Hardness number & \% of elongation \\
\hline 96 & 4 & 121.45 & 147 & 10.26 \\
\hline 94 & 6 & 129 & 152 & 14.56 \\
\hline 92 & & & & \\
\hline 90 & 8 & 131.37 & 157 & 6.02 \\
\hline
\end{tabular}

\begin{tabular}{|l|l|l|l|}
\hline$\%$ of aluminium & \% of copper & $\begin{array}{l}\text { Izod impact energy } \\
\text { Joules }\end{array}$ & $\begin{array}{l}\text { Charpy } \\
\text { impact energy joules }\end{array}$ \\
\hline 96 & 4 & 6 & 3 \\
\hline 94 & 6 & 3 & 8 \\
\hline 92 & 8 & 8 & 10 \\
\hline 90 & 10 & 2 & 2 \\
\hline
\end{tabular}




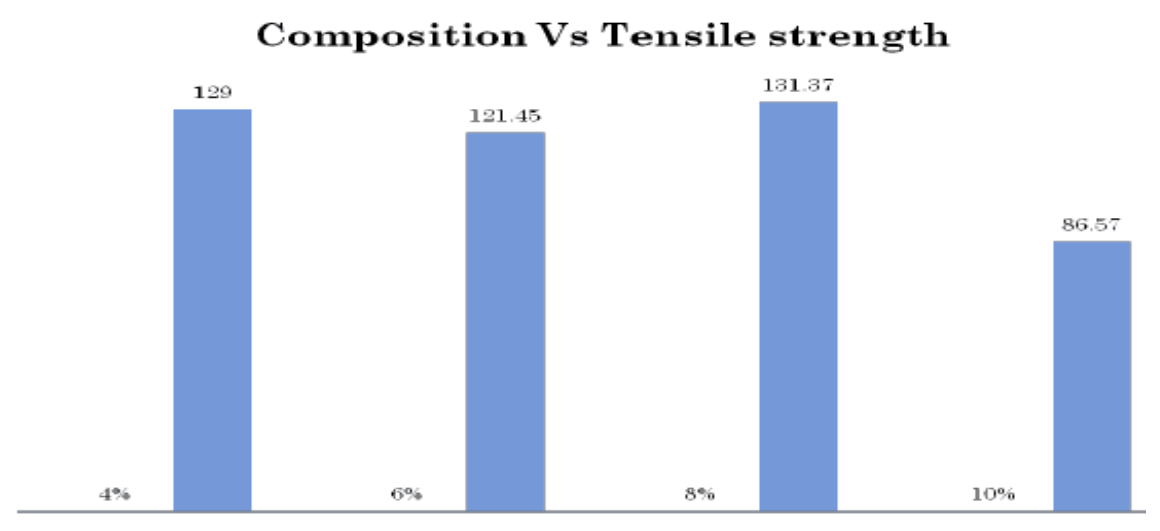

Composition Vs \% of elongation
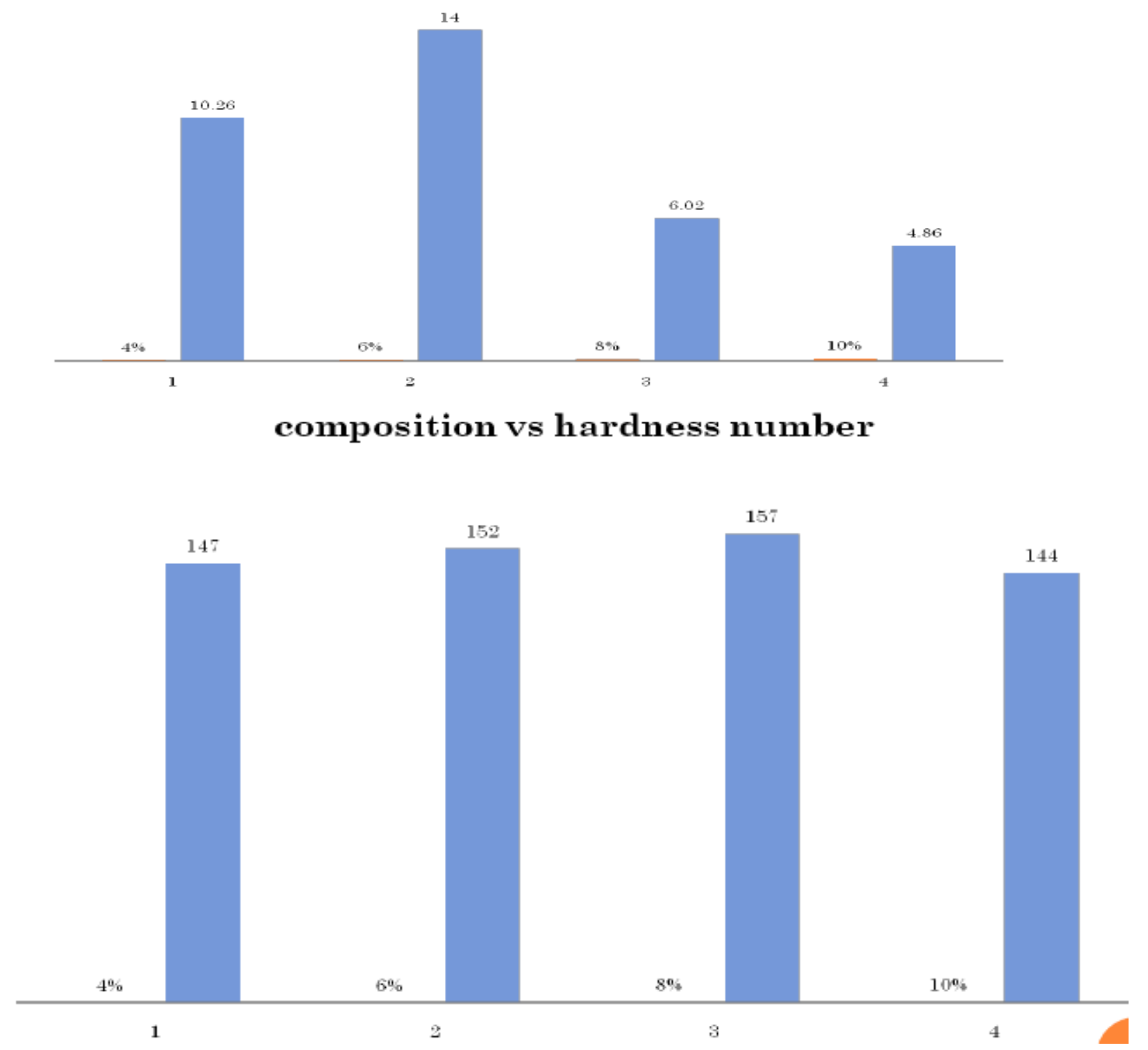

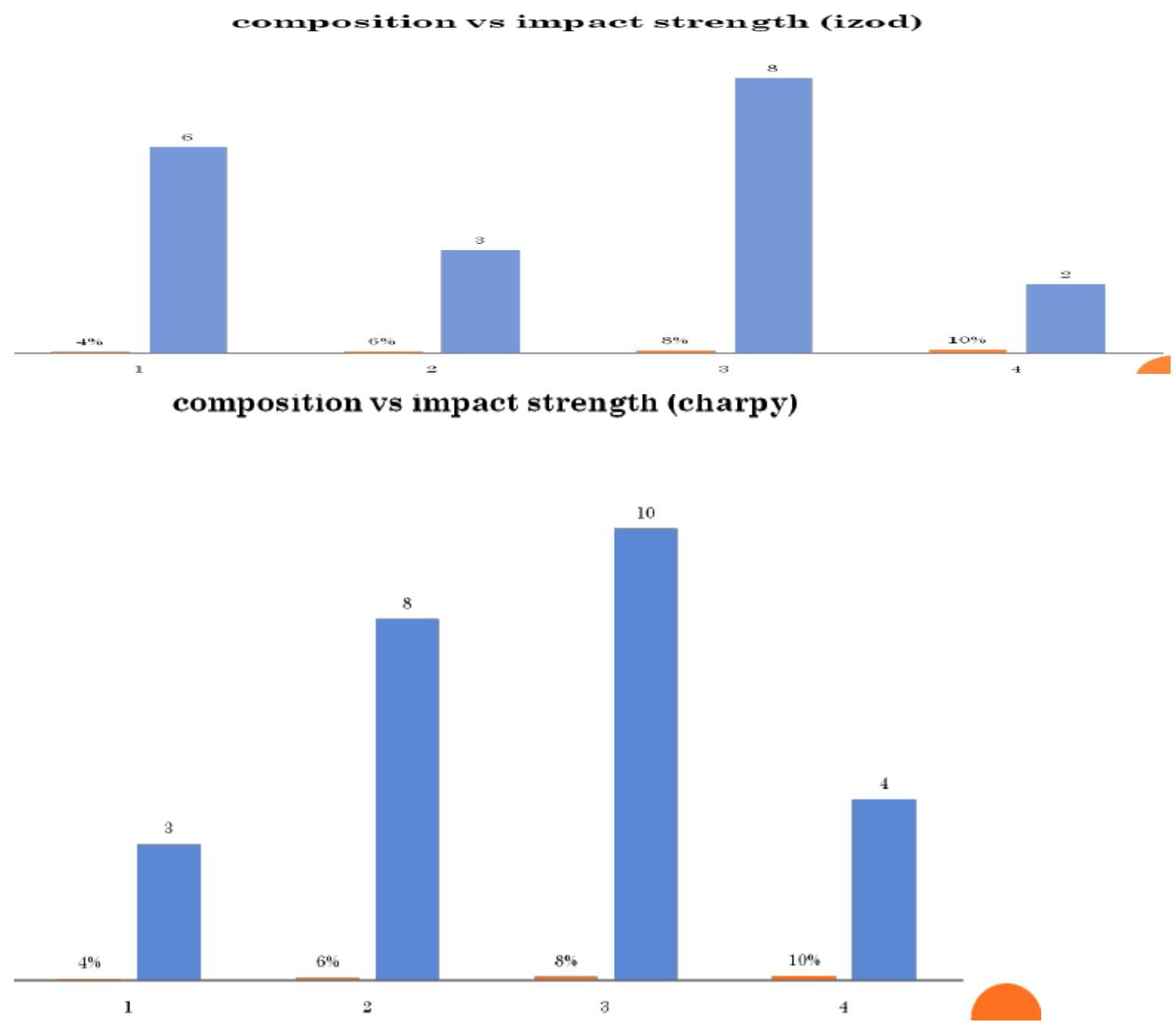

\section{IV.CONCLUSION}

Aluminum with $8 \%$ Copper composition having the better tensile strength, hardness and good impact strength which are especially useful for Aerospace applications.

Metal Matrix Composites (MMCs) have evoked a keen interest in recent times for potential applications in aerospace and automotive industries owing to their superior strength to weight

ratio and high temperature resistance. The widespread adoption of particulate metal matrix composites for engineering applications has been hindered by the high cost of producing components. Although several technical challenges exist with casting technology yet it can be used to overcome this problem.

From results it is observed that for $8 \%$ Copper with Aluminium tensile strength is $131.37 \mathrm{~N} / \mathrm{mm}^{\wedge} 2$, hardness number is 157 , percentage of elongation is 6.02, impact izod energy absorbed is 8 joules and impact charpy energy absorbed is 10 joules which shows that the properties with $8 \%$ copper are more optimal when compared with other compositions so we opted for $8 \%$ copper.

\section{REFERENCES}

[1]. Ashby, Michael et al. MATERIALS, ENGINEERING, SCIENCE, PROCESSING AND DESIGN. Oxford: Butterworth-Heinemann, 1999. Prof Ashby has written various college-level textbooks on materials science, including this one.

[2]. Budinski, Kenneth G. and Michael K. Budinski. Engineering Materials: Properties and Science . New Jersey: Prentice Hall, 2010. A comprehensive intro.

[3]. Polmear, Ian. Light alloys from Traditional Alloys to Nano crystals. Oxford: Butterworth-Heinemann, 2005. A good book about aerospace-type alloys (aluminum, magnesium, titanium alloys). 
[4]. ASM Materials Information Society: A society for thousands of materials engineers worldwide.

[5]. The Minerals, Metals and Material Society: US-based organization for minerals and materials professional.

[6]. Krishnaiah, A, Uday Chakkingal and P. Venugopal (2007) "Microstructure and Mechanical Properties of Commercial Purity Copper Resulting from Repeated Groove Pressing followed by Cold Rolling", Materials Science Forum, 539543, 2198-2203. 